\title{
Review on Broadening Genetic Pool of Open Pollinated Maize (Zea mays L.) Varieties and Inbridline Development
}

\author{
Netsanet Abera Muluneh \\ Ethiopian Institute of Agricultural Research, Pawe Agricultural Research Center, P.O.Box 25
}

\begin{abstract}
Maize is the most important cereal crop grown and consumed worldwide. Open pollinated maize varieties are increasingly becoming more important and popular among resource-poor farmers due to their low cost. Maize breeding programme should continue in developing inbred lines from maize OPVs to achieve greater genetic improvement. However, recently the proportion of released open pollinated varieties (OPVs) versus hybrids for farmers is continuously decreasing as compared to the past 10 years. Therefore, it has become important to broaden the genetic pool of open pollinated maize varieties by introducing germplasm from abroad, characterizing phenotypically using agronomic per se and checking their stability across different environments.
\end{abstract}

Keywords: OPVs, Phynotypic characterization, Heterotic grouping, Yield stability

DOI: $10.7176 / \mathrm{JBAH} / 9-17-01$

Publication date:September $30^{\text {th }} 2019$

\section{INTRODUCTION}

\subsection{Maize crop and its center of origin}

Maize (Zea mays L.) is an open pollinated annual cereal crop. It belongs to the grass family Poaceae, genus Zea and species mays (L.) [1], [2]. The genus Zea (L.) has been examined and found to majorly have $2 n=20$ chromosomes [3]. Maize plant has a large genome of about 2.3 - 2.7 Giga base pairs (Gbp) with a total number of gene estimated to be between 42,000 and 56,000 [4]. The center of origin of maize is believed to be the Mesoamerican region in the Mexican highlands, from where it rapidly spread to other parts of the globe [5]. Maize is a versatile crop, growing across a wide range of environments.

\subsection{Economic importance of maize}

Maize is the most important cereal crop in sub-Saharan Africa (SSA) where it is an important staple food for more than 1.2 billion people and plays an important role in the diet of millions of African populations [6]. Compared with other major cereal crops, maize is proficient in taking advantage of sunlight and enabling it to grow quicker [7]. These characteristics makes it highly productive and among the food crops with maximum photosynthetic rates [8]. Maize is capable of producing maximum grain yield per unit area compared to all other cereal crops[9]. Maize kernel contains about $72 \%$ starch, $10 \%$ protein, and $4 \%$ fat, supplying an energy density of $365 \mathrm{Kcal} / 100 \mathrm{~g}$, as compared to rice $(360 \mathrm{Kcal} / 10 \mathrm{~g})$ and wheat $(340 \mathrm{Kcal} / 100 \mathrm{~g})$. However, maize kernel endosperm protein content is lower than wheat and rice. Maize provides many of the B vitamins and essential minerals along with fibre. However, maize is deficient in vitamin $\mathrm{B}_{12}$ and vitamin $\mathrm{C}$ and is generally a poor source of calcium, folate, and iron [10]. Worldwide, almost $66 \%$ of maize is used to provide feed for domestic animals, $25 \%$ for human consumption and $9 \%$ for manufacturing purposes.

In the United States of America, maize is one of the most important crops in terms of acreage harvested and agricultural output [11]. According to reports from Renewable Fuels Association [12] the use of cereal crops for industrial purposes (such as biofuel production) has increased by more than $26 \%$. The Organization for Economic Co-operation and Development (OECD) and FAO [13] reported that ethanol in US and China is expected to be produced predominantly from maize. Likewise, in the European Union, it is assumed that ethanol will be made mostly from maize and wheat. Additionally, the World Food Programme, the Red Cross and the UN High Commission for Refugees also buy substantial amount of maize grain from Uganda to use in food aid programmes in nearby African countries [14], [15]. Manda et al. (2014) reported that agricultural commodities including maize grain are Uganda's leading informal exports to Kenya estimated at $65.4 \%$ of total Informal Cross Border Trade (ICBT), estimated at US\$ 56.2 million. The maize grain informally exported to Kenya is estimated to be 58, 212 tones, with an estimated value of US\$10.3 million.

\section{Phenotypic characterization of maize traits}

Open pollinated maize varieties are highly heterogeneous and hence morphologically more variable than singlecross hybrids. Information on the phenotypic diversity within and between the breeding material and the genetic distances between available germplasm is important for deciding which method will be applied in breeding programmes. The phenotype of an individual is determined by the effect of its genotype and environment. Maize has enormous genetic diversity that offers incredible opportunities for genetic enhancement [17].

The existence of the database on phenotypic characterization according to the principles of the UPOV (International Union for the Protection of New Varieties of Plants) descriptor also allows the comparison of 
genotypes that have been observed during different temporal periods and in situations when different example varieties were used. This characterization can be obtain through visual assessment of a single measurement on a group of plants or parts of plants, a measurement of a number of individual plants and by the observation of individual plants or parts of the plant [18]. Phenotypic characterisation can be used to identify desirable genotypes for their traits of interest for example plant height, ear height, number of ears per plant, pest or disease resistance, tolerance to heat and drought; to identify the adaptation level of the tested genotypes on a given agro ecology and to better understand and use the relationships among genotypes for crop improvement [19].

Of these phenotypic traits, plant and ear height play important roles in plant lodging. Therefore, maize breeders give special attention to these two traits in maize breeding [20]. Low plant height and central or near to central placement of the top ear on the plant is desired, because such plants are less vulnerable to lodging and hence could contribute to enhanced grain yield. Plant height and ear height can be measured any time between 2 and 3 weeks after flowering until just prior to harvest, depending on your work schedule [21]-[23]. They are one of the most heritable and accurately predictable and easily measured traits in maize breeding [24]. Plant and ear height are strongly associated with flowering date, both morphologically and ontogenetically, because internodes formation stops at floral initiation, which means that earlier flowering maize is usually shorter [25].

Another important trait in maize breeding is the flowering period. It can be defined as the time span between the beginning of the first pollen shed and the last wilted silks [26]. Unlike other cereal crops, the male and female flowers of maize are distinctly separated. This allows cross pollination and the massive level of hybrid maize production which is based on the exploitation of hybrid vigour [27], wide-ranging morphological variation [8], and hereditary plasticity and diversity [28]. If maize is flowering during hot, dry weather this places extra stress on the plant's resources and the silks may wither and burn off before the pollen reaches the ear. Hence fertilisation does not occur for all kernels and seed set is greatly reduced. This is commonly referred to as pollen blasting [22], [29], [30]. Days to anthesis and silking, anthesis to silking interval (ASI) and days to maturity are some of those important flowering related phenotypic traits which are critical in generating early to medium maturing commercial varieties. According to Setimela et al., (2014), early maturing maize varieties are able to yield fairly well because they mature before the detrimental effects from drought intensify and hence they are ideal crop varieties for food security. Anthesisi to silking interval measures the time difference in days between pollen shed and silk emergence. It is highly correlated with grain yield and has a high heritability under drought stress and hence flowering in maize is a crucial trait in breeding for drought tolerance. It is during flowering and pollination, when there is a high demand for water to ensure grain filling so low ASI is very important trait in maize breeding [32]. A study done in Kenya by [19] demonstrated that ASI was significantly negatively correlated with grain yield (GY). Earliness and high yield were considered to be in reciprocal ratio to each other and there was also a positive correlation between earliness and stress tolerance. The higher the ear is, the later the plant matures, but earliness and lower ear height have no absolute reciprocal effect [26].

Concerning the grain yield and related traits, grain yield is a complex phenomenon which results from the interaction of various contributing factors [33]. It is a result of kernel number plant ${ }^{-1}$ (KNP) and kernel weight plant $^{-1}(\mathrm{KWP})$ at harvest. Various studies have evaluated the relationship between grain yield and yield parameters [34]. In maize, grain yield is closely associated with number of ears and kernels at harvest [35] and is primarily correlated to KNP [36]. The endosperm occupies about two thirds of a maize kernel's volume and accounts for approximately $86 \%$ of its dry weight. The endosperm of maize kernels can be yellow or white. The primary component of endosperm is starch, together with $10 \%$ bound protein (gluten), and this stored starch is the basis of the maize kernel's nutritional uses [29]. Grain yield at $12.5 \%$ moisture content can be calculated on a plot basis using the following formula [33]:

Grain yield (kg/ha) $(12.5 \%)=\frac{\text { F.W.(kg /plot) }(100-\mathrm{MC}) \times \mathrm{S} \times 10,000}{(100-12.5) \times \mathrm{har}}$

Where, F.W. = Fresh weight of ear in kg at harvest, $\mathrm{MC}=$ Grain moisture content at harvest, $\mathrm{S}=$ Shelling coefficient (0.80), moisture content required in grain at storage $12.5 \%, 1$ hectare $=10,000 \mathrm{~m}^{2}$, Area/plot $=3.75 \mathrm{~m}^{2}$ with $5 \mathrm{~m}$ long, $0.75 \mathrm{~m}$ wide and 2 row plot.

Finally, from disease and related traits, maize streak virus (MSV) is one of the most important diseases that cause a leaf disease in maize. It is a serious threat to maize production on the African continent [37]. Maize plants are vulnerable to infection from emergence to tasselling, but the stage at which infection occurs is important [38]. Virus infection at early crop stages may result in total crop loss. Transmission of MSV to a plant host is accomplished only by sap-feeding leafhoppers. Once in the plant, the virus multiples and moves in the sap above the point where infection occurred, causing characteristic streaking in the leaves above. MSV can infect many crops such as maize, oats, barley, wheat, rye, teff, sorghum, pearl millet, napier grass and finger millet. Many noncrop grasses are also natural hosts. Maize plants infected within 3 weeks of emergence become stunted and may die early or produce small poorly filled ears. Infection after 8 weeks usually has little or no visible effect on vigour or productivity of the plants. The main symptom of MSV is broken to almost continuous, narrow chlorotic streaks centred on leaf veins. The amount of the streaking varies according to maize hybrid or variety. In susceptible 
varieties, noticeable irregular or continuous streaks are distributed uniformly over the leaf surface of infected leaves. The parallel, yellowish streaks may partially or almost completely combine, leaving irregular green lines centred between small veins [39].

Turcicum leaf blight or northern corn leaf blight (NCLB) is another important disease that is caused by a number of fungal diseases affecting photosynthesis with severe reduction in grain yield to an extent of 28 to $91 \%$ [40]. Yield loss is caused predominantly through the loss of photosynthetic leaf area due to blighting. If NCLB establishes before silking and spreads to upper leaves during grain filling, severe yield losses can occur [41]. NCLB disease starts first on lower leaves and then spread up the whole plant under favourable weather conditions. High humidity associated with low temperature and cloudy weather is favourable conditions for disease development on the host plant. Heavy dew on the growing plant also as supportive factors to lead NCLB disease severity [42]. Disease symptoms first appear on the leaves at any stage of plant growth, but usually at or after anthesis [43].

\section{Heterotic grouping of OPVs}

A heterotic group is a group of related or unrelated genotypes displaying similar combining ability and giving a heterotic response when crossed to an opposite or other genetically distinct germplasm group. It comprises of a set of genotypes that perform well when crossed with genotypes from a different heterotic group. The choice of heterotic groups is fundamental because heterotic groups and heterotic patterns are important tools for exploiting heterosis of the trait of interest [44]. Theoretical and experimental evidences suggest that grouping of germplasm into divergent heterotic groups is advantageous due to (i) a higher mean heterosis and hybrid performance and (ii) a reduced specific combining ability (SCA) variance and a lower ratio of SCA to general combining ability (GCA) variance [45]. In hybrid maize breeding, information on genetic diversity and heterotic groups is very useful in inbred line development and germplasm evaluation for planning crosses for hybrid cultivar development. The classification of elite germplasm and inbred lines into different heterotic groups is an important task in any breeding program. The inbreeding level of the population from which the families are selected, the number and type of families selected, and the procedure employed in intermating them to form OPVs have a direct effect on the level of inbreeding of the resulting OPVs. Use of fewer families makes it easier to ensure that they are truly superior and similar in morphological traits because it depends on the number of times each landrace is used in the formation of the OPVs. Therefore, the open pollinated varieties can share the same heterotic groups [46].

Looking at the history of successful heterotic patterns in various crops, there is evidence suggesting that genetically diverse populations isolated by time, space, or pedigree are the most promising candidates for heterotic patterns identification. Therefore, the high level of heterosis in a cross indicates that parents are more genetically diverse than those of crosses that show little or low heterosis [47]. Heterosis in sorghum has been reported in the form of increased grain and forage yields, hastened flowering and maturity, increased height and larger stems and panicles [48]. [49] conducted a study to determine levels of heterosis and identify parents for use in sorghum hybrid production in East Africa. They (Ringo et al) generated 121 experimental hybrids in a line $\times$ tester mating design and evaluated them in multi locations. There were significant differences among locations, crosses and male parents for all the characters studied. Grain yield showed average heterosis of up to $81.90 \%$ expressed in ICSA $11 \times$ S35. The parent ICSB11 and S35 were selected because they produced hybrids that yielded high with medium height and maturity. An investigation done by Rajendran et al., (2014) reported the heterotic grouping and patterning in quality protein maize inbreds. Based on yield specific combing ability, they [47] classified 6 parental inbreds into 3 heterotic groups.

\section{YIELD STABILITY}

Maize remains the food security crop in worldwide predominantly grown by the resource-constrained and smallscale farmers. Newly introduced and local OPVs including their newly generated top crosses should exhibit great yield potential and average stability over a wide range of agro-ecologies. Maize productivity is function of genotype, environment and the genotype $\times$ environment interaction [50], [51]. The differential response of a genotype across environments is defined as the genotype $(\mathrm{G}) \times$ environment $(\mathrm{E})$ interaction GEI; [52] and Bernardo and Rueda (2002) indicated that it is the rule in most quantitative characteristics. Grain yield in nature, routinely exhibits GxE interaction [54] which necessitates evaluation of cultivars in multiple environments [55], [56]. Crop cultivars are grown in diverse environments of different soil types, soil fertility levels, moisture levels, temperatures and cultural practices. During production, all these cumulated conditions constitute the growing environment for the crop varieties [57].

Additionally, the existence of GEI necessitates that breeders evaluate genotypes in more than one environment to obtain repeatable rankings of genotypes. High genotype by environmental interaction (GEI) leads to differential response and stability among genotypes. In maize breeding, choice of a suitable candidate cultivar is subject to two considerations: (1) high grain yield across a wide range of environments and (2) consistent performance over environments. Consistency of performance is dependent upon the GEI. Cultivars, which show less GEI are described as more stable or well buffered. Stability of yield is defined as the ability of a genotype to 
avoid substantial fluctuations in yield over a range of environment [58]. Cultivar performance is a function of the genotype and the nature of the production environment [59]. The effects that genotypes and environments exert on genotype environment interactions ( $\mathrm{G}$ x E) are statistically non-additive, indicating that differences in yields among cultivars will depend on the environment [60].

Major difference in genotypes stability is due to crossover interaction effect of genotype and environment; therefore, changes in their rank are various in different environmental conditions [61]. The Genotype $x$ Environment Interaction ( $\mathrm{G} \times \mathrm{E}$ ) study is therefore an important common phenomenon in maize, especially when yield stability of hybrids is going to be studied [62]. Genotype $\times$ environment (GE) interaction is an important issue faced by plant breeders in crop breeding programs. Genotype $\times$ environment (GE) interaction is an important issue faced by plant breeders in crop breeding programs [63]. In addition to genotype and environment main effects, performance of cultivars is also determined by the GEI, which is a differential response of cultivars to environmental changes [64], [65]. However, Karnataka (2012) suggested that, the cause of yield stability often is unclear but the mechanisms of stability fall into four general categories, genetic heterogeneity, yield component compensation, stress tolerance and capacity to recover rapidly from stress. Since the phenotype of the hybrid is the resultant of Genotype $(\mathrm{G}) \times$ Environment $(\mathrm{E})$, a large $\mathrm{G} \times \mathrm{E}$ interaction effect causes problem to the breeder in selecting a genotype with consistent performance across environments. The performance of a genotype is determined by three factors: genotypic main effect $(\mathrm{G})$, environmental main effect (E) and their interaction(GE) [67]. Large GEI is expected when genotypes are grown under a wide range of environments and outside their normal zone of adaptation [68].

\section{Recommendations}

The first step in broadening the genetic pool of OPVs should be phenotypic characterization followed by evaluation of genotypes in different agro ecologies. Considering unpredictability of environmental conditions, breeding for yield stability and other agronomic characteristics remains the most important way in maize breeding program. Due to the eternally changing climatic conditions, it is necessary to develop varieties that show stability in grain yield and in different agronomic aspects in a wide range of environments. A genotype with consistent performance provides a reasonable yield in adverse environmental conditions. So evaluating genotypes in many locations $(\mathrm{G} x$ E) is very important to determine stability which in turn increases the number of genotypes that can be released for production. A cereal breeding programme should continue in developing inbred lines from open pollinated maize germplasm to achieve greater genetic improvement. Evaluation should be done over multiple environments and more than two seasons to achieve higher genotype stability. To achieve better results in a short time, regional and international collaboration is also required. Materials that have been proved stabile can be incorporated into the breeding programme to broaden the genetic pool of OPV and to exploit their maximum genetic potential.

\section{Reference}

[1] OECD, "Consensus Document on the Biology of Zea mays subsp. mays (Maize) Environment," Paris, 2003.

[2] USDA, "Germplasm Reseorces Information Network-(GRIN) [Online Data Base],"

[3] H. K. Chaudhary, B. Gnanesh, Belaghihalli, N.Fetch, J. Mitchell, and T. Zegeye, "Alien Gene Transfer in Crop Plants," Alien Gene Transf. Crop Plants, vol. 2, pp. 51-73, 2014.

[4] T. Sharma, B. Kanika, B. S. Mienda, A. Yahya, I. A. Galadima, and M. S. Shamsir, "Research Journal of Pharmaceutical, Biological and Chemical Sciences," Microb. Res. Lab. Dep. Bot. M.L.S. Univ. Udaipur313001 Rajasthan, India., vol. 6, no. 2, pp. 934-956, 2015.

[5] Y. Matsuoka, Y. Vigouroux, M. M. Goodman, J. Sanchez G, E. Buckler, and J. Doebley, "A single domestication for maize shown by multilocus microsatellite genotyping.," Proc. Natl. Acad. Sci. U. S. A., vol. 99, no. 9, pp. 6080-6084, 2002.

[6] FAO, FAO Statistical Yearbook, 2012th ed. Rome, 2013.

[7] R. Kapoor and C. Batra, "Genetic Variability and Association Studies in Maize ( Zea mays L .) for Green Fodder Yield and Quality Traits," Electron. J. Plant Breed., vol. 6, no. 1, pp. 233-240, 2015.

[8] R. J. Salvador, "Maize," In: The Encyclopedia of Culture and Society of Mexico. Fitzrov Dearborn Publishers, 1997. .

[9] N. Taj, S. Ajmal, and R. Saleem, "Yield Performance of Single / Double Crosses and F2 Progenies in Maize ( Zea mays L.),” J. Agric. Res., vol. 50, no. 4, pp. 469-476, 2012.

[10] E. T. Nuss and S. A. Tanumihardjo, "Maize: A paramount Staple Crop in the Context of Global Nutrition," Compr. Rev. Food Sci. Food Saf., vol. 9, no. 4, pp. 417-436, 2010.

[11] A. Nadal and T. A. Wise, "The Environmental Costs of Agricultural Trade Liberalization: Mexico-U.S. Maize Trade Under NAFTA," Mexico, 2004.

[12] RFA, "Accelerating industry innovation: 2012 ethanol industry outlook," 2007.

[13] OECD and FAO, "Food and Agriculture Organization of the United Nations," FRANCE, 2007.

[14] CIMS/Foodnet, "A preliminary study of the maize marketing system in Uganda and the design of a market 
information system," 1999.

[15] S. Ferris and P. Robbins, "Developing marketing information services in Eastern Africa The FOODNET experience Local , National and Regional market information services," Int. Inst. Trop. Agric., no. May, pp. 1-96, 2004.

[16] C. Manda, J. Knowles, J. Connors, and S. Mwombela, "Borders : Social Interaction and Economic and Political Integration of the East African Community," 2014.

[17] B. M. Prasanna, "Diversity in global maize germplasm: Characterization and utilization," J. Biosci., vol. 37, no. 5, pp. 843-855, 2012.

[18] V. Babic, M. Babic, M. Filipovic, N. Delic, and V. Andjelkovic, "Phenotypic Characterization and Relatedness of Maize Inbred Lines," Genetika, vol. 40, no. 3, pp. 227-236, 2008.

[19] K. Ngugi, H. D. Q. G. Hrujh, and K. Zd, "Anthesis to Silking Interval Usefulness in Developing Drought Tolerant Maize,” J. Renew. Agric., vol. 1, no. 5, pp. 84-90, 2013.

[20] C. Szoke, Z. Zsubori, Z. Gyenes, H. O. Illes, I. Pok, and F. Racz, "Inheritance of Plant and Ear Height in Maize (Zea Mays L.)," Acta Agrar. Debreceniensis, vol. 8, pp. 34-38, 2002.

[21] CIMMYT, "Managing Trials and Reporting Data for CIMMYT's International Maize Testing Program," Mexico, 1999.

[22] ABARE, "The Biology of Zea mays L . ssp mays," Canberra, 2008.

[23] P. Jean, "Maize production," ARC-Grain Crop. Inst., pp. 1-38, 2003.

[24] J. a. Peiffer et al., "The Genetic Architecture Of Maize Height," Genetics, vol. 196, no. 4, pp. 1337-1356, 2014.

[25] O. B. Bello, S. Y. Abdulmaliq, M. S. Afolabi, and S. A. Ige, "Correlation and Path Coefficient Analysis of Yield and Agronomic Characters among Open Pollinated Maize Varieties and Their F1 Hybrids in a Diallel Cross," African J. Biotechnol., vol. 9, no. 18, pp. 2633-2639, 2010.

[26] J. Ransom, “Corn Corn Corn," Agron. - Cereal Crop. NDSU Ext. Serv., vol. 2, no. May, pp. 1-8, 2013.

[27] B. C. Mandal, "Maize breeding and Seed Production Manual," Korea and Mongolia 6, 2014.

[28] V. . Chopra and S. Prakash, "Zea Introduction," Evolution and adaptation of cereal crops.Science Publishers Inc, NH, USA., 2002.

[29] MAEFI, "Biology of Maize," Ministry of science and Technology Government India, 2010.

[30] Q. Wen-Zeng et al., "Morphological and physiological characteristics of corn (Zea mays L.) roots from cultivars with different yield potentials," Eur. J. Agron., vol. 38, pp. 54-63, 2012.

[31] P. S. Setimela et al., "Variability of Grain-Filling Traits in Early Maturing CIMMYT Tropical Maize Inbred Lines," Crop Sci. Soc. Am., vol. 54, no. april, pp. 530-536, 2014.

[32] G. O. Edmeades, "Progress in Achieving and Delivering Drought Tolerance in Maize - An Update by," Int. Serv. Acquis. Agri-biotech Appl., pp. 1-44, 2013.

[33] M. Noor, H. Rahman, M. Iqbal, I. A. Shah, and F. Ali, "Evidence of Improving Yield and Morphological Attributes via Half-Sib Family Recurrent Selection in Maize," Am. J. Exp. Agric., vol. 3, no. 3, pp. 557-570, 2013.

[34] G. F. Liu, J. Yang, H. M. Xu, Y. Hayat, and J. Zhu, "Genetic analysis of grain yield conditioned on its component traits in rice (Oryza sativa L.)," Aust. J. Agric. Res., vol. 59, no. 2, pp. 189-195, 2008.

[35] K. D. Subedi and B. L. Ma, "Ear Position, Leaf Area, and Contribution of Individual Leaves to Grain Yield in Conventional and Leafy Maize Hybrids," Crop Sci., vol. 45, no. 6, pp. 2246-2257, 2005.

[36] I. J. Biosci, R. S. Sharifi, Y. Raei, and W. Weisany, "Study of Physiological Growth Indices in Maize ( Zea mays L .) Hybrids under Different Plant Densities,” vol. 5, no. 2220-6655, pp. 100-109, 2014.

[37] E. N. Nwankwo, R. I. Egwuatu, N. J. Okonkwo, and B. A. Boateng, "Screening of Ten Maize Varieties, Zea Mays (L.) For Resistance Against Prostephanus truncatus (Horn) (Coleoptera: Bostrichidae) from Different Zones of Nigeria and Ghana," Acad. J. Entomol., vol. 7, no. 1, pp. 17-26, 2014.

[38] J. Derera, G. Abalo, P. Tongoona, and R. Edema, "A Comparative Analysis of Conventional and MarkerAssisted Selection Methods in Breeding Maize Streak Virus Resistance in Maize," Crop Sci. Soc. Am., vol. 49, no. April, pp. 509-520, 2009.

[39] PHII, "Field facts from pioneer Hi-Brid International," vol. 5, no. 6, pp. 2-4, 2010.

[40] T. R. Reddy, P. N. Reddy, R. R. Reddy, and S. S. Reddy, "Management of Turcicum Leaf Blight of Maize Caused by Exserohilum Turcicum in Maize," Int. J. Sci. Res. Publ., vol. 3, no. 10, pp. 1-4, 2013.

[41] K. Rikus and T. Stephanie, "Northern Corn Leaf Blight," 2011.

[42] R. Singh, R. P. Srivastava, and R. Lekha, "Nothern Corn Leaf Blight- An Important Disease of Maize : An Extension Fact Sheet," Indian Res. J. Ext. Educ., vol. 2, no. special, pp. 334-337, 2012.

[43] S. Harlapur, M. Kulkarni, B. Patil, M. Wali, S. Kulkarni, and Y. Hegde, "Effect of Turcicum Leaf Blight Incidence on Host Physiology in Maize," Karnataka J. Agric. Sci., vol. 20, no. 4, pp. 869-870, 2010.

[44] D. B. Gurung, M. L. C. George, and Q. D. Delacruz, "Determination of Heterotic Groups in Nepalese Yellow Maize Populations,” Nepal J. Sci. Technol., vol. 10, pp. 1-8, 2009. 
[45] J. C. Reif, A. R. Hallauer, and A. E. Melchinger, "Heterosis and Heterotic Patterns in Maize," Maydica, vol. 50, no. February, pp. 215-223, 2005.

[46] M. Warburton et al., "Genetic Diversity in CIMMYT Nontemperate Maize Germplasm : Landraces, Open Pollinated Varieties, and Inbred Lines," Crop Sci. Soc. Am., vol. 48, no. April, pp. 617-624, 2008.

[47] A. Rajendran, A. Muthiah, J. Joel, P. Shanmugasundaram, and D. Raju, "Heterotic grouping and patterning of quality protein maize inbreds based on genetic and molecular marker studies," Turkish J. Biol., vol. 38, pp. 10-20, 2014.

[48] T. W. Pfeiffer, M. J. Bitzer, J. J. Toy, and J. F. Pedersen, "Heterosis in sweet sorghum and selection of a new sweet sorghum hybrid for use in syrup production in appalachia," Crop Sci., vol. 50, no. 5, pp. 1788-1794, 2010.

[49] J. Ringo et al., "Heterosis for yield and its components in sorghum (Sorghum bicolor L. Moench) hybrids in dry lands and sub-humid environments of East Africa," Aust. J. Crop Sci., vol. 9, no. 1, pp. 9-13, 2015.

[50] H. Namorato, G. V. Miranda, L. V. De Souza, L. R. Oliveira, and R. O. Delima, "Comparing Biplot Multivariate Analyses with Eberhart and Russell "Method for Genotype x Environment Interaction," Biotechnology, vol. 9, pp. 299-307, 2009.

[51] A. Deitos, E. Arnhold, F. Mora, and G. V. Miranda, "Yield and Combining Ability of Maize Cultivars under Different Ecogeographic Conditions," Crop Breed. Appl. Biotechnol., vol. 6, no. 3, pp. 222-227, 2006.

[52] Y. Beyene et al., "Genotype by Environment interactions and Yield Stability of Stem Borer Resistant Maize Hybrids in Kenya," African J. Biotechnol., vol. 10, no. 23, pp. 4752-4758, 2011.

[53] J. M. Bernardo and R. Rueda, "Bayesian hypothesis testing: A reference approach," Int. Stat. Rev., vol. 70, no. 3, pp. 351-- 372, 2002.

[54] I. A. Khalil et al., "Evaluation of Maize Hybrids for Grain Yield Stability in North-West of Pakistan," Sarhad J. Agric., vol. 27, no. 2, pp. 213-218, 2011.

[55] X. Fan, M. S. Kang, H. Chen, Y. Zhang, J. Tan, and C. Xu, "Yield Stability of Maize Hybrids Evaluated in Multi-Environment Trials in Yunnan, China," Am. Soc. Agron., vol. 99, pp. 220-228, 2007.

[56] T. Bacha, "Genotype X Environment Interaction and Yield Stabliity of Breade Wheat ( Triticum Eastivum L .) Genotype in Ethiopia using the Ammi Analisis," J. Biol. Agric. Healthc., vol. 5, no. 11, pp. 129-140, 2015.

[57] M. S. Abdulai, P. Y. K. Sallah, and O. Safo-Kantanka, "Maize Grain Yield Stability Analysis in Full Season Lowland Maize in Ghana," Int. J. Agric. Biol., vol. 9, no. 1, pp. 41-45, 2007.

[58] M. S. Kang, "Using Genotype by Environment Interaction for Crop Cultivar Development.," Adv. Agron., vol. 62, pp. 199-246., 1998.

[59] M. Cooper and D. E. Byth, "Understanding plant adaptation to achieve systematic applied crop improvementA fundamental challenge in "Plant adaptation and crop improvement,"” CAB Int. IRRI, UK., pp. 5-23, 1996.

[60] C. A. Scapim, V. R. Oliveira, A. De Lucca, and C. D. Cruz, "Yield Stability in Maize (Zea mays L.) and Correlations among the Parameters of the Eberhart and Russell, Lin and Binns and Huehn models," Genet. Mol. Biol., vol. 23, no. 2, pp. 387-393, 2000.

[61]M. Shahryarinasab and R. Chogan, "Stability Analysis of Maize Yield by using Unvariate Statistical Method," Biol. Forum - An Int. J., vol. 7, no. 1, pp. 394-399, 2015.

[62] W. Abera, V. Rensburg, M. Labuschagne, and H. Maartens, "Genotype-Environment Interactions and Phenotypic Stability Analyses of Linseed in Ethiopia,” S.Afri. J. Plant Soil., vol. 71, no. 4, pp. 66-71, 2004.

[63] E. Emami, E. Farshadfar, and H. Safari, "GGEBiplot Analysis of Genotype $\times$ Environment Interaction in Agropyron Intermedium,” J. Biodivers. Environ. Sci., vol. 6, no. 4, pp. 260-267, 2015.

[64] A. R. Hallauer, C. Marcelo, and M. Filho, Quantitative Genetics in Maize Breeding. 2010.

[65] M. Dettori, J. Crossa, K. Ammar, R. J. Peña, and M. Varela, "Three-Mode Principal Component Analysis of Genotype-by-Environment-by-Trait Data in Durum Wheat,” J. Crop Improv., vol. 25, no. 6, pp. 619-649, 2011.

[66] J. Karnataka, "Genetic studies on stability among maize inbred lines Maize is the third most important cereal crop of the world and so also in India. In the recent years, there has been a in the country. Since, maize is a highly cross pollinated it offers However ," Agric. Sci, vol. 25, no. 1, pp. 124-126, 2012.

[67] W. Yan, M. S. Kang, B. Ma, S. Woods, and P. L. Cornelius, "GGE Biplot vs AMMI Analysis of Genotypeby-Environment Data," Crop Sci, vol. 47, no. April, pp. 641-653, 2007.

[68] H. C. Becker and J. Leon, "Stability Analysis in Plant Breeding," Plant Breed., vol. 101, no. April, pp. 1-23, 1988. 